\title{
Comparative Study of the Live Weight and Linear Body Measurement in Red Sokoto Goat Ecoytpes
}

\author{
Umar $\mathrm{AA}^{1}$, Atabo SM${ }^{2 *}$, Danmaigoro $\mathrm{A}^{1}$ and Hena $\mathrm{SA}^{3}$ \\ ${ }^{1}$ Department of Veterinary Anatomy, Usmanu Danfodiyo University, Nigeria \\ 2Department of Animal Health and Production Technology, College of Agriculture \\ and Animal Science Bakura, Zamfara-Nigeria
}

\section{Research Article}

Volume 2 Issue 1

Received Date: December 24, 2017

Published Date: January 31, 2018

${ }^{3}$ Department of Veterinary Anatomy, Faculty of Veterinary Medicine, University of JOS, Nigeria

*Corresponding author: Shaibu Mohammed Atabo, Department of Animal Health and Production Technology, College of Agriculture and Animal Science Bakura, Zamfara-Nigeria, Tel: +2348069728062; E-mail: mohakosh@yahoo.com

\section{Abstract}

This study was performed to determine the live weight and linear body measurement in the five coats colored red Sokoto goat ecotypes. For this purpose, a total of 200 goats were used, and classified into five (5) different groups of coat colored ecotypes and subgroups (males and females). The result showed that dark red coat colored goats had significantly higher mean body weight than the other coat colors $(\mathrm{p}<0.05)$. BW and CVRL in dark red were significantly higher compared to the other ecotypes. However, variegated coat colored red Sokoto goat had significantly higher HW compared to the others except the dark red coat colors, furthermore, variegated coat colored red Sokoto goat also had significantly higher CC compared to all the red Sokoto goat ecotypes. It was concluded that dark red and variegated coat colored goat had similar linear body measurements and dark red Sokoto goat ecotypes was recommended for goat production.

Keywords: Crown Vertebral Rump Length (CVRL); Height at Withers (HW); Chest Circumference (CC); Coat Color Ecotypes; Dark Red; Brown; Light Brown; Black and Variegated

\section{Introduction}

The importance of goats in the economy of developing countries is enormous. It has been found that there are breed differences in term of the quality and quantity of meat, milk and skin production [1]. Indigenous breeds of goats in Nigeria include; the West African Dwarf (WAD) goat, Sahel/desert goat- (West African Long-Legged) and Sokoto Red/Maradi [2]. Distribution of the goat breeds in the country showed that the West African Dwarf (WAD) goat is common to southern Nigeria while the Sahel or desert goat and Sokoto Red are common to the northern region of the country [3].

Five distinct coat colors were identified as Red Sokoto Goat (RSG) ecotypes; dark red, brown, light brown, black and variegated [4], these colors currently represent the population of red Sokoto goat with only about $19 \%$ of the total population found within Sokoto and its environs are classified as dark red Sokoto goat [4].

Characterization of goats breeds were made basically on their origin, body size, body length and other linear 
body measurement. The Nigerian goats are classified into large, medium and small breeds that is Sahel, red Sokoto and West African Dwarf breeds respectively based on height at withers $[5,6]$.

Body weight and linear body measurement of red Sokoto goat has been reported by several authors in Ibadan, Maiduguri and Adamawa Nigeria [7-10]. However no information available on these measurements in the different coat colors in red Sokoto goat. More so, there is need to establish these morphometric data to bridge the gap of the existing information, the data to be generated in this study will further establish means of differentiating between the five coat color of red Sokoto goat for selective breeding, this data will also serve as a baseline information for estimating a one year old red Sokoto goat of the five different coat colors.

Therefore, this study determined the bodyweight and linear body measurements across the different coat colors of red Sokoto goat.

\section{Materials and Methods}

In this study, two hundred (200) goats with an average age of one year kept at the Usmanu Danfodiyo University farm were used, they were classified into five (5) groups based their coat color ecotypes; group 1 (dark red), group 2 (brown), group 3 (light brown), group 4 (black) and group 5 (variegated) [4] (Table 1). The age of the animals were determined using rostral dentition and time of birth
[11] and their weight was obtained using a weighing balance (CAMRY ${ }^{\circledR}$ ) [12].

The following Linear Body Measurement was obtained:

Crown Vertebral Rump length (CVRL): was measured using a tape rule (BUTTERFLY ${ }^{\circledR}$ ) from the inter-cornual protuberance to the base of the tail.

Chest Circumference (CC): was obtained by running the tape rule around the thoracic cage behind the olecranon and over the contour of the withers.

Height at Withers (HW): was measured when the animal was standing quietly on a ground level. The tape rule was placed on the ground level lateral to the distal phalanx to the peak contour above the shoulder blade [8].

\section{Statistical analysis}

Data obtained were subjected to Analysis of Variance (ANOVA), using GraphPad InStat statistical software version 3.0. Difference was considered significant at $\mathrm{P}<0.05$. $\mathrm{BW}=$ Body weight, $\mathrm{CVRL}=$ Crown Vertebral Rump Length, HW=height at withers and $\mathrm{CC}=$ Chest circumference. Means in the same row with different superscript differ significantly $(\mathrm{p}<0.05)$

\section{Results}

The results on body weight (BW), crown vertebral rump length (CVRL), height at withers (HW) and chest circumference (CC) for the five different coat color ecotypes are presented in (Table 1).

\begin{tabular}{|c|c|c|c|c|c|}
\hline & Dark red & Brown & Light browrn & Black & Variagated \\
\hline BW & $20.44 \pm 4.86^{\mathrm{a}}$ & $19.14 \pm 4.60^{\mathrm{b}}$ & $18.19 \pm 5.01^{\mathrm{c}}$ & $19.53 \pm 5.24^{\mathrm{b}}$ & $18.83 \pm 4.87 \mathrm{bc}$ \\
\hline CVRL & $78.46 \pm 8.35^{\mathrm{a}}$ & $76.78 \pm 9.53^{\mathrm{a}}$ & $75.57 \pm 9.39^{\mathrm{a}}$ & $75.52 \pm 11.00^{\mathrm{a}}$ & $77.88 \pm 7.35^{\mathrm{b}}$ \\
\hline HH & $60.75 \pm 1.67^{\mathrm{a}}$ & $56.84 \pm 2.80^{\mathrm{b}}$ & $56.34 \pm 5.08^{\mathrm{b}}$ & $56.4 \pm 1.87^{\mathrm{b}}$ & $61.38 \pm 2.37^{\mathrm{a}}$ \\
\hline CC & $60.84 \pm 5.18^{\mathrm{a}}$ & $59.84 \pm 5.41^{\mathrm{a}}$ & $59.74 \pm 5.61^{\mathrm{a}}$ & $59.72 \pm 5.08^{\mathrm{a}}$ & $62.91 \pm 3.87^{\mathrm{b}}$ \\
\hline
\end{tabular}

Table 1: Mean \pm SD of body weight (BW) (kg), crown vertebral rump length (CVRL) (cm), height at withers (HW) (cm) and chest circumference (CC) (cm) of the five different coat color goats. BW=Body weight, CVRL=Crown Vertebral Rump Length, HW=height at withers and CC=Chest circumference. Means in the same row with different superscript differ significantly $(\mathrm{p}<0.05)$. 


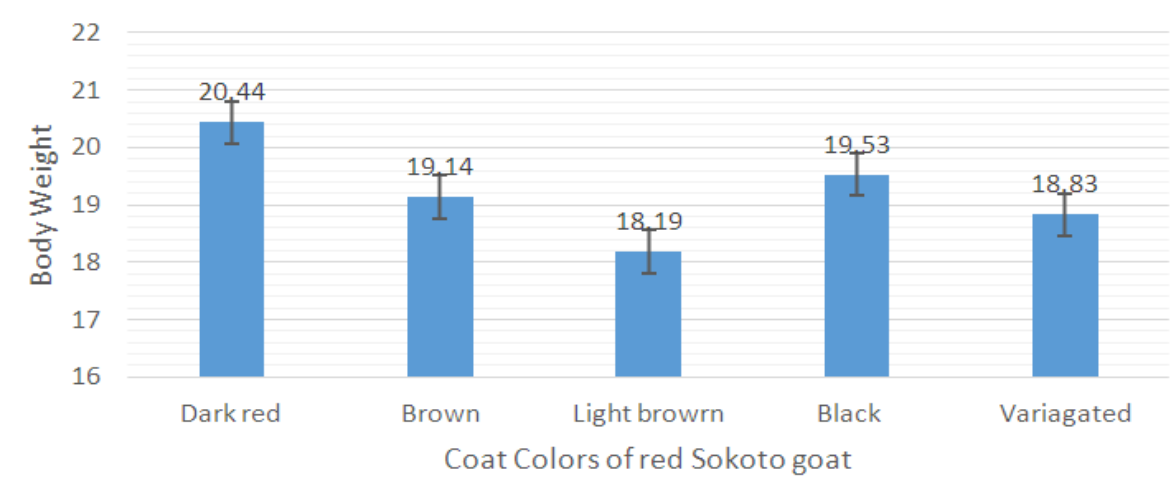

Figure 1: Body weight (kg) of the five (5) coat colors of red Sokoto goat ecotypes.

All the coat color ecotypes, dark red males had the highest body weight (BW) (20.44 \pm ) and differs significantly $(\mathrm{P}<0.05)$ with the other four male coat colored ecotypes, and no significant $(\mathrm{P}<0.05)$ difference was seen between the brown, black and variegated and between the light brown and variegated (Table 1 and Figure 1).

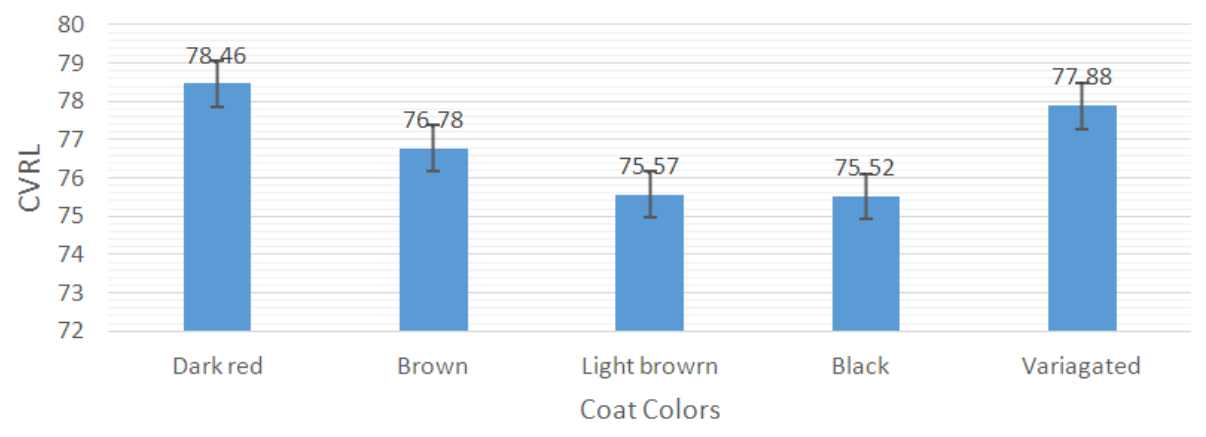

Figure 2: Crown Vertebral Rump Length (CVRL) (cm) of the five (5) coat colors of red Sokoto goat ecotypes.

The dark red had the highest CVRL (78.46 \pm 8.35$)$ and it differs significantly $(\mathrm{P}<0.05)$ compared to the other male coat colored ecotypes except the variegated (77.88 \pm 7.35$)$. (Table 1 and Figure 2).

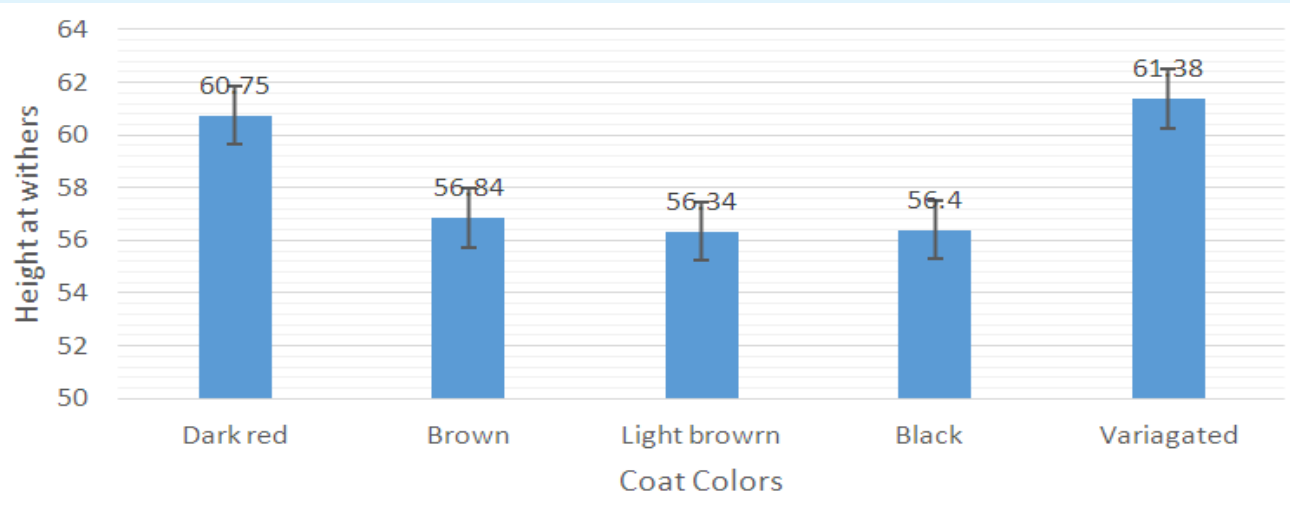

Figure 3: Height at withers (HW) $(\mathrm{cm})$ of the five (5) coat colors of red Sokoto goat ecotypes. 
The dark red coat colored ecotypes differs significantly with the other coat colors except the variegated who had the highest mean HW $(61.38 \pm 2.37)$ (Table 1 and Figure $3)$.

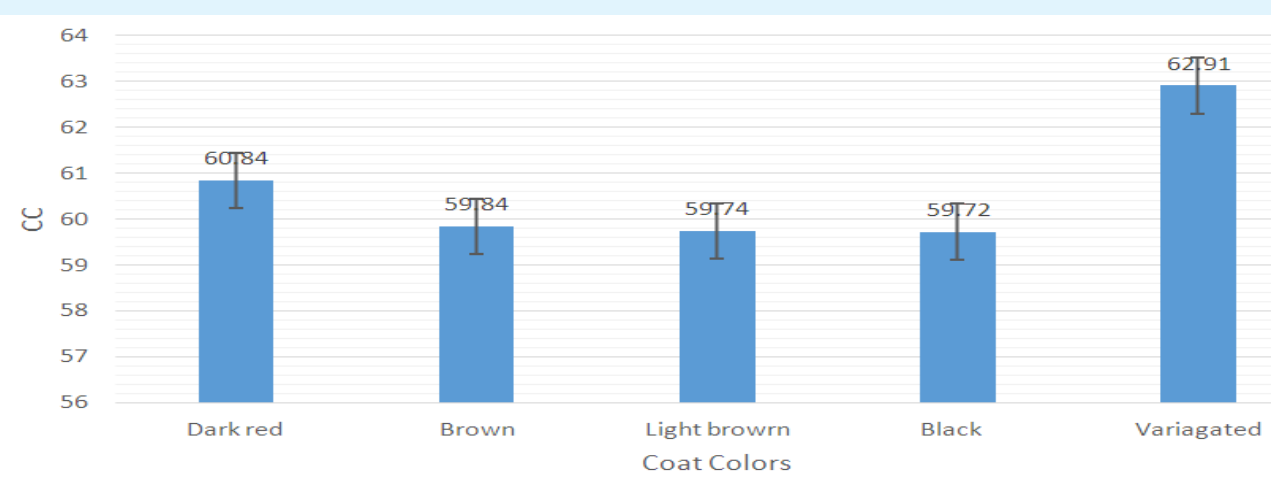

Figure 4: Chest circumference (CC) (cm) of the five (5) coat colors of red Sokoto goat ecotypes.

The variegated coat color ecotypes had the highest mean chest circumference (CC) and differs significantly $(\mathrm{P}<0.05)$ with the other four coat color ecotypes (Table 1 and Figure 4).

\section{Discussion}

Body weight (BW) and other linear body measurements of height at withers (HW), Chest circumference (CC) and Crown vertebral rump length (CVRL) were determined with respect to sex, age and coat colour, with the aim of characterizing the red Sokoto goat ecotypes. Phenotypically, the red Sokoto goats have been characterized as a medium breed with ab adult height at withers of about $64 \mathrm{~cm}$ and average age body weight of about $23-30 \mathrm{~kg}$ [13] which is consistent with the findings of this study. Furthermore, in all the five ecotypes identified, the CC measurements showed significantly higher values in variegated than the other four coat colors. These findings of the present study agreed with several studies conducted on linear body measurements [13-17]. Similarly, the values obtained for CC and HW in all the ecotypes agrees with other work [7], but disagrees with the CVRL. However, the BW, HW and CC in this study were generally higher than those reported in white Borno goat and red Sokoto goat [8]. Generally these differences could be due to the management system, feeding, age range and genetic differences. In all the five ecotypes, BW and CVRL in dark red were significantly higher compared to the other ecotypes. However, variegated coat colored red Sokoto goat had significantly higher HW compared to others except the dark red coat colors, furthermore, variegated coat colored red Sokoto goat also had significantly higher coat colors compred to all the red
Sokoto goat ecotypes. It was concluded that dark red and variegated coat colored goat had similar linear body measurements and dark red Sokoto goat ecotypes was recommended for goat production.

\section{References}

1. Davendra C (1981) Meat production from goats in developing countries. BSAP Occ Publ 1(4): 395-406.

2. Aina ABJ, Oppong D (2011) Performance evaluation of West African Dwarf goat fed "kau" (Local potash) based diet as a dietary mineral source. Ghana J Animal Production 9(3): 49-67.

3. Fabusoro E (2006) Property Rights, Access to Natural Resources and Livelihood Security among settled Fulani Agro-pastoralists in Southwestern Nigeria, Research Report for International Foundation for Science. Institutions for Collective Action among Settled Fulani Agro-Pastoralists in Southwest Nigeria.

4. Umar AA, Sonfada ML, Kwari HD (2013) Ecotypes of the Red Sokoto Goat based on coat color, Anatomy and Surgery poster presentation during $50^{\text {th }}$ Annual congress of Nigerian Vet. Medical Association, at International Conference Centre, Abuja, Nigeria.

5. Davendra C, Mcleroy GI (1982) Goat and Sheep Production in the Tropics. Longman London, pp: 35.

6. Resource inventory and management limited (RIM) (1992) Nigerian National Livestock Resources Survey. Federal Department of Livestock and Pest Control Sercvices, Abuja, Nigeria, 4: 287. 
7. Babale DM, Kibon A, Yahaya MS (2015) Performance and linear body measurements of Red Sokoto male goats on replacement levels of corn cobs for maize bran with cowpea husk basal diet. Net J Agricult Sci 3(2):35-40.

8. Adeyinka IA, Mohammed ID (2006a) Relationship of Live weight and Linear Body Measurement in Two Breeds of Goats of Northern Nigeria. J Ani Vet Advances 5(11): 891-893.

9. Adeyinka IA, Mohammed ID (2006b) Accuracy of Body Weight Prediction in Nigerian Red Sokoto Goats Raised in North Eastern Nigerian Using Linear Body Measurement. Pakistan J Biological Sci 9(15): 28282830.

10. Ajo EO, Akinyemi M O, Ewuola EO, Osaiyuwu $\mathrm{OH}$ (2014) Body measurement of Red Sokoto Bucks in Nigeria and Their Relationship with Testicular Biometrics. Iranian J Applied Ani Sci 4(4): 761-767.

11. Umar AA, Atabo SM, Sonfada ML (2017) Rostral Dental Eruption Pattern in Red Sokoto Goat Ecotypes. Vom J Vet Sci 13(1).

12. Dyce KM, Sack WO, Wensing CJG (2010) Textbook of Veterinary Anatomy $4^{\text {th }}(E d n$.$) , Saunders Elsevier, pp:$ 71-78.
13. Robinet AH (1967) La Cherre rousse de Maradi son Exploitatio et sa place dan I' economie et l' elevage dela Republique du Nigeru. Rev d'elev Med Vet pays trop 20(1): 129-186.

14. Hassan A, Ciroma A (1988) Body Weight Measurements Relationship in Nigerian Red Sokoto Goats. African Small ruminant Research 22(7): 169175.

15. Osinowo OA, Buvanendra V, Koning NL (1988) A study of coat type, pigmentation and wattle incidence in yankasa sheep and their effects on fertility and weaning weight. Paper presentation at the $13^{\text {th }}$ Annual Conference of the Nige. Soc. For Animal Production held at the University of Calabar 20-24th march, pp: 10.

16. Odubote IK (1994) Characteristic of the West African Dwarf Goat for certain qualitative traits. Nig J Ani Production 21: 37-40.

17. Kwari HD (2001) A morphological Study of the Ecotypes of Sahel Goats in Borno State with special reference to Sexual Dimorphism. A PhD Thesis, Department of Veterinary Anatomy, Faculty of Medicine, University of Maiduguri, Borno State Nigeria. 